\title{
Introduction
}

\section{Guideline update for the performance of fusion procedures for degenerative disease of the lumbar spine}

\author{
Michael W. Groff, M.D.
}

\begin{abstract}
Department of Neurosurgery, Brigham and Women's Hospital, Boston, Massachusetts
\end{abstract}

On behalf of the American Association of Neurological Surgeons/Congress of Neurological Surgeons (AANS/CNS) Joint Section on Disorders of the Spine and Peripheral Nerves, it is with distinct pleasure that I introduce the "Guideline update for the performance of fusion procedures for degenerative disease of the lumbar spine." The initial version of these guidelines was originally published in the June 2005 issue of the Journal of Neurosurgery: Spine. ${ }^{1}$ The update presented in this issue of the Journal of Neurosurgery: Spine exemplifies the commitment that organized neurosurgery, in cooperation with our orthopedic colleagues, has made to ensure that this vital source of information continues to evolve and reflect the most current evidence on each of the topics covered.

In a very real sense these guidelines are a credit to all clinicians involved in the care of disorders of the spine. That is the body of work on which the literature is based, which in turn is the foundation of these guidelines. This work is also a credit to the established infrastructure created by the Guidelines Committee of the AANS and CNS to facilitate the production and dissemination of evidence-based guidelines. In addition, the successful publication of this material would not have been possible without the assistance provided by the staff at the Journal of Neurosurgery Publishing Group. Their expertise in the peer-review process, editorial guidance, and transmission of information have enhanced the overall quality and impact of this effort. I personally want to thank Dr. James
T. Rutka, M.D., Ph.D., Editor-in-Chief of the Journal of Neurosurgery: Spine, for his forbearance and attention to this project.

As the literature has evolved, so too has the process of guidelines development. As there is no well-accepted standard protocol for updating guidelines, a significant amount of time and effort was expended to establish the methodology. Consensus among members of the expert panel was achieved in accord with a well-defined methodology to minimize bias, maximize integrity, and create a final product consistent with the highest ideals of evidence-based medicine. Among the most important missions of the AANS/CNS Joint Section on Disorders of the Spine and Peripheral Nerves is the generation of highquality evidence that can assist both our membership and the spine community at large in providing the highestquality care for our patients. Just as this work builds on the foundation created by the original 2005 publication, it is anticipated that this document will in time be updated as well. For the moment, however, it reflects an unbiased synthesis of the literature and points toward the quality spine care that we, as clinicians, aspire to provide.

It is an honor to present this Guideline Update on behalf of the AANS/CNS Joint Section on Disorders of the Spine and Peripheral Nerves to the readership of the Journal of Neurosurgery: Spine. This update reflects the highest ideals of the section. It is offered to physicians of all levels who seek a greater understanding of the role lumbar fusion can play in the care of patients with degenerative disease of the lumbar spine.

(http://thejns.org/doi/abs/10.3171/2014.4.SPINE14190)

\section{Disclosure}

Dr. Groff is a consultant for DePuy Spine and Biomet Spine.

\section{Reference}

1. Heary RF: Introduction to the guidelines for the performance of fusion procedures for degenerative disease of the lumbar spine. J Neurosurg Spine 2:636, 2005 